\section{ACID FOR METABOLIC CONJUGATION}

Glucuronic Acid, Free and Combined

Chemistry, Biochemistry, Pharmacology and Medicine. Edited by Geoffrey J. Dutton. Pp. xviii +629. (New York: Academic Press, Inc.; London: Academic Press, Inc. (London), Ltd., 1966.) 200s.

THE reader will agree that no defence is necessary for considering glucuronic acid to be a glucose metabolite of biochemical interest in its own right. Acceptance of this view will facilitate further progress in research of the role of this acid in living matter. Although historically glucuronic acid has been considered for a long time to be a conjugating radical made available by the body for detoxification purposes, this process is currently seen simply as one of the many recognized metabolic conjugations which have biochemical significance.

This book represents a valuable compilation of the published work relating to glucuronic acid, and some of the chapters are outstanding. One of these is the first chapter, by Marsh, discoverer of the saccharolactone pathway of glucuronic acid metabolism, which represents an authoritative, exhaustive but nevertheless readable treatment of the chemistry of $\mathrm{D}$-glucuronic acid and its glycosides. There is an encyclopaedic list of all the glucosiduronic acids reported in the literature, and the degree of completeness of the evidence in support of their nature is indicated.

A central chapter written by the editor of the book is an honest, detailed survey of the development of our understanding of the mechanisms of glucuronic acid transfer reactions. That this understanding is far from complete is obvious when anyone searches for information about the nature of the enzyme UDP glucuronyl transferase and about the kinetics of the reaction it catalyses. In these circumstances resort to legal terms, such as "inadmissible evidence", seems out of place in the absence of all the facts regarding the nature of the transferase(s). Here, also, "multiplicity" of transferases seems to lack biochemical definition.

Levvy and Conchies's noteworthy studies on aldonolactone inhibition of glycosidases are included. Their statement that the lysosome theory begs the whole question of the in vivo action of acid hydrolases will fall on an increasing number of receptive ears today.

Jayle and Pasqualini's review of steroids and thyroxine, Silbert's of polysaccharides, Smith and Williams's of drugs and Schmidt and Lester's of bilirubin, are all written in a manner which is both informative and readable. A valuable feature of the book is the collection of analytical methods at the end of several chapters. I recommend the book for the serious student and investigator in biochemistry, pharmacology and medicine.

\section{Wirliam H. Fishman}

\section{COMPOUNDS HOLD TOGETHER}

\section{Structure and Bonding}

Vol. 1. Edited by C. K. Jørgensen, J. B. Neilands, R. S. Nyholm, D. Reinen and R. J. P. Williams. Pp. 281. (Berlin and New York: Springer-Verlag, 1966.) 48 D.M.

THIS new review series is intended to appear at irregular intervals and to deal with problems in chemical structure and bonding in modern inorganic chemistry, chemical physics and biochemistry.

The first volume contains nine reviews received between January and May 1966. "Recent Progress in Ligand Field Theory", by C. K. Jørgensen, is based on lectures given at the Summer School on Ligand Field Theory held at Constance in September 1962. This gives a brief account of the interpretation of electronic spectra of transition metal complexes and of refinements of electrostatic ligand field theory. "The Ambident Nature of Cyanide", by D. F. Shriver, is a clear review of structures containing the bifunctional cyanide ligand.

Three fully documented biochemical articles occupy half the volume. "Naturally Occurring Non-porphyrin Iron Compounds", by J. B. Neilands, deals mainly with iron(III) hydroxamates. These stable complexes seem to carry iron through metabolic channels and insert it into porphyrins, enzymes and proteins. "The Chemistry and Function of Ferredoxin" is by B. B. Buchanan, and describes the non-haem iron protein, which plays an important part in the action of anaerobic fermentative bacteria, in photosynthetic bacteria and in plant photosynthesis. "The Transferrins", by R. E. Feeney and S. K. Komatsu, concerns the homologous proteins found in various fluids of vertebrate animals; for example, blood serum, milk and egg-white (conalbumin).

Three of the final group of four articles are revised versions of lectures given at the Symposium on Soft and Hard Acids and Bases held at the Cynamide European Research Institute at Cologny in May 1965. "Factors Contributing to (b)-behaviour in Acceptors", by S. Ahrland, resembles another article by the same author (Svensk Kemisk Tidskrift, 77, 584; 1965) and is an outgrowth of Ahrland, Chatt and Davies's original division of metal ions into classes $(a)$ and $(b)$ on the basis of their affinity sequences for donor atoms. "The Classification of Acceptors and Donors in Inorganic Reactions", contributed by R. J. P. Williams and J. D. Hale, is a more critical account of the inter-relations of the $(a)$ and $(b)$ classification, Pearson's hard and soft terminology and polarizability. "Electronic Polarizability, Innocent Ligands and Spectroscopic Oxidation States", by C. K. Jørgensen, also discusses these concepts. Finally, there is "Displacement Reactions and the Concept of Soft and Hard Acids and Bases", by R. F. Hudson, which describes correlations of rate constants with various properties of nucleophiles.

The first volume has no index and the five editors have not quite achieved a common format. It is not yet clear whether this particular marriage of chemistry and biochemistry will be happy. The soft back is rather highly priced for the individual, but is an essential purchase for chemical and biochemical libraries. It contains much to interest, stimulate and provoke. F. J. C. Rossotri

\section{IMMUNOLOGICAL DANGER}

\section{Delayed Hypersensitivity}

By J. L. Turk. (North-Holland Research Monographs: Frontiers of Biology, Vol. 4.) Pp.ix +252. (Amsterdam: North-Holland Publishing Company, 1967.) $80 s$.

Sxmposia on delayed hypersensitivity commonly begin with a discussion of the definition of the term. This usually ends inconclusively, and accurately indicates our confusion and lack of understanding of this phenomenon. Hypersensitivity, however, is commonly defined as an immunological reaction harmful to the body, and the term "delayed" refers to the interval that is observed between the injection of antigen into a sensitized animal and the development of an inflammatory reaction at this site. The phenomenon was first described as characteristic of hypersensitivity to bacteria and was initially termed "bacterial allergy". The phrase "delayed-type hypersensitivity" was introduced by Chase, who obtained such delayed, slowly developing reactions, not only with bacteria but also with purified antigens of various types. The next crucial finding was again made by Chase who, in collaboration with Landsteiner, discovered that passive transfer of delayed-type hypersensitivity could not be achieved with serum, that is circulating antibodies, but could be so transferred with lymphoid cells or cells from 